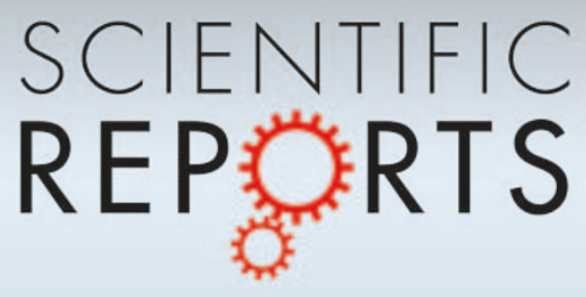

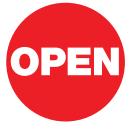

SUBJECT AREAS:

SMALL RNA'S

MOLECULAR BIOLOGY

MATERIALS

MOLECULAR ENGINEERING

Received

30 September 2011

Accepted

10 February 2012

Published

28 February 2012

Correspondence and requests for materials should be addressed to K.I. (kazuto-ikemoto@ mgc.co.jp)

\section{Collision of millimetre droplets induces DNA and protein transfection into cells}

\author{
Kazuto Ikemoto' , Ichiro Sakata ${ }^{2}$ \& Takafumi Sakai ${ }^{2}$
}

'Niigata Research Laboratory, Mitsubishi Gas Chemical Company, Inc., 182 Tayuuhama Shinwari, Kita-ku, Niigata, Japan,
${ }^{2}$ Graduate School of Science and Engineering, Division of Life Science, Saitama University, 255 Shimo-ohkubo, Saitama, Japan.

Nonperturbing and simple transfection methods are important for modern techniques used in biotechnology. Recently, we reported that electrospraying can be applied to DNA transfection in cell lines, bacteria, and chicken embryos. However, the transfection efficiency was only about $2 \%$. To improve the transfection rate, physical properties of the sprayed droplets were studied in different variations of the method. We describe a highly efficient technique (30-93\%) for introduction of materials such as DNA and protein into living cells by electrospraying droplets of a high conductivity liquid onto cells incubated with the material for transfection. Electric conductivity has a sizable influence on the success of transfection. In contrast, molecular weight of the transfected material, types of ions in the electrospray solution, and the osmotic pressure do not influence transfection efficiency. The physical analysis revealed that collision of cells with millimetre-sized droplets activates intracellular uptake.

imple DNA transfection methods that are effective in living cells are fundamentally important in modern biotechnological research. For many scientific questions, transfection has been the experimental basis for important studies on gene function. Most commonly used transfection methods require the use of technologies smaller than the cells themselves, in which artificial nanometre-scale materials and technologies (known as nanotechnologies) are employed. Examples are cationic polymers ${ }^{1}$, liposomes ${ }^{2}$, gold particles used with gene guns $^{3}$, and lasers ${ }^{4}$. In a typical technique, a chemical carrier component forms molecular complexes or particles with DNA, which are then transported into cells by endocytosis. A problem with such techniques is that they can induce marked changes in cells and may be cytotoxic. In addition, although these methods increase energy in only a limited part of the cell, the stimulation is too strong and thus the energy output is high.

Electrospray ionization (ESI) is frequently used in analysis by mass spectrometry (MS) ${ }^{5,6}$, and it has many industrial applications in the manufacture of small materials $\mathrm{s}^{7,8}$. In a previous study, we reported that a mixture of cells and DNA that had been electrosprayed could have applications as a technique for minimally destructive transfection of cell lines, bacteria, and chicken embryos?. However, despite the remarkable advantages of transfection with electrospray, including simplicity of the electrospray device, no requirement for a cytotoxic carrier reagent, and simple protocol, improvements are needed to address the limitations in transfection efficiency (approximately $2 \%$ in cultured cells). The underlying mechanism of this method was considered to be that small droplets acted in a similar manner to a gene gun or desorption electrospray ionization (DESI). Our method does not spray a solution of DNA; rather, cells preincubated with DNA are electrosprayed with a liquid free from DNA. In this study, we have examined the potential of various electrospray solutions and conditions for improving the transfection efficiency, and we have further studied the mechanism.

\section{Results}

Electrospray Device. Electrospray is performed by applying a high voltage to a metal nozzle through which a medium is propelled. A charged drop at the tip of the nozzle splits the stream into small droplets, and charged aerosol is accelerated by a high voltage electric field. For transfection, the liquid droplets are sprayed onto a preincubated mixture of cells and plasmid DNA. The nozzle is moved in order to spray the entire surface of the dish. An electrolyte that is nontoxic for the cells is suitable for spraying. However, it has been reported that a highly conductive solution is not suitable for electrospray ionization because any substance with conductivity greater than $10^{-3} \mathrm{~S} / \mathrm{cm}$ cannot be dispersed ${ }^{10,11}$.

It is assumed that the electrical discharge from the flowing liquid and metal nozzle diminishes the electric field intensity. Moreover, it was found that the metallic nozzle used for electrospraying, either with or without a liquid medium, generated an electric current $(60 \mu \mathrm{A},-15 \mathrm{kv})$ that flowed as a discharge, and this discharge was causing 
damage to plasmid DNA. The damage of supercoiled plasmid was the same as that reported for ESI-MS of DNA ${ }^{12}$. To overcome this problem, we employed an insulated nozzle that separates the droplet from the edge of the electrode, which prevents electrostatic breakdown. The insulated nozzle did not cause DNA damage, and the electric current of its discharge dropped by half. In addition, it is thought that the lower discharge would be better for cell viability. This device enables electrospraying with a high concentration of electrolyte (over $100 \mathrm{mS} / \mathrm{cm}$ ). The relationships between conductivity of electrolyte (spraying medium), size of droplets, and efficiency of transfection are shown graphically in Figure 1, as well as fluorescent micrographs of cells expressing GFP.

Solvent effect in electrospray transfection. Standard experimental conditions were used to study the effects of different spraying solutions on transfection efficiency. Chinese hamster ovary (CHO) cells preincubated with plasmid pEGFP-N1 were electrosprayed with the solution by moving the nozzle at $5 \mathrm{~mm} / \mathrm{s}$ and under $6-\mathrm{mm}$ intervals scanning, at a liquid flow rate of $6 \mathrm{~mL} / \mathrm{h}$.

a) The effect on transfection efficiency of various spray media, such as water, nutrient media, normal and high-concentration phosphate-buffered saline (PBS), dissolved sugar, and solutions of specific electrolytes, such as organic cations, salt, and phosphates, was examined by electrospray at $-12 \mathrm{kV}$. The results of this examination are shown in Table 1 . The transfection efficiency was checked by calculating the number of GFP-positive cells per total cells. This efficiency for our technique was found to be $10^{5}$ cells transfected per microgram of plasmid DNA.

Nonionic $20 \%(\mathrm{w} / \mathrm{w})$ sucrose resulted in an efficiency of $1 \%$; monosaccharides (glucose and fructose), sugar alcohols (sorbitol and xylitol), and organic solvents (DMSO, methoxyethanol, and propyleneglycol) gave similar results. An amino sugar electrolyte solution of $5 \%(\mathrm{w} / \mathrm{w})$ glucosamine and alpha-MEM resulted in an efficiency of $25 \%$. In contrast, high concentrations of sodium chloride and phosphate yielded an efficiency of $>60 \%$ (Figure 2). We compared it with the efficiency of other transfection methods.
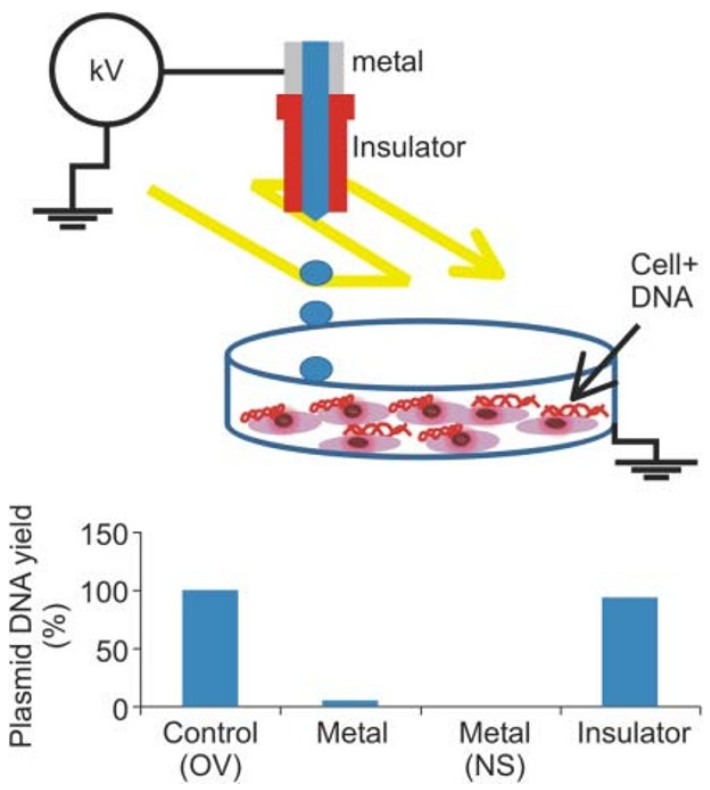

Figure $1 \mid$ (a) Scanning electrospray device. The insulator (PEEK) nozzle (calibre: $0.25 \mathrm{~mm}$, length: $20 \mathrm{~mm}$ ) was used to spray the $35-\mathrm{mm}$ dish.

(b) Stability of plasmid in nozzle material. Plasmid DNA (super coil type, $90 \%$ including) based yield. Water $(100 \mu \mathrm{L})$ was sprayed on $3.5-\mathrm{cm}$ polystyrene dish including pEGFP-N1(100 $\mu \mathrm{g} / 300 \mu \mathrm{L}$ water $)$ from $2 \mathrm{~cm}$ height for $1 \mathrm{~min}$. After spray, the sample was electrophoresed. No spray (NS) was strong damage to DNA by discharge.

\begin{tabular}{|c|c|}
\hline & $\begin{array}{l}\text { Efficiency } \\
(\%)\end{array}$ \\
\hline 1 Water $100 \% \mathrm{H}_{2} \mathrm{O}$ & 0.8 \\
\hline $220 \%$ sucrose & 1.3 \\
\hline $3 \alpha$-MEM (major components $0.68 \% \mathrm{NaCl}, 0.1 \%$ Glucose) & 25 \\
\hline $45 \%$ glucosamine $\mathrm{HCl}$ & 25 \\
\hline $5 \mathrm{PBS}\left(0.9 \% \mathrm{NaCl}, 0.0144 \% \mathrm{KH}_{2} \mathrm{PO}_{4}, 0.0795 \% \mathrm{Na}_{2} \mathrm{HPO}_{4}\right)$ & 48 \\
\hline $62.5 \% \mathrm{NaH}_{2} \mathrm{PO}_{4}+2.5 \% \mathrm{Na}_{2} \mathrm{HPO}_{4}$ & 61 \\
\hline $74.5 \% \mathrm{NaCl}$ & 67 \\
\hline $83 X$ PBS (PBS of the 3 times concentration) & 68 \\
\hline $95 \mathrm{X}$ PBS (PBS of the 5 times concentration) & 69 \\
\hline $1010 X$ PBS (PBS of the 10 times concentration) & 42 \\
\hline
\end{tabular}

Transfection efficiency was $0.2 \%$ for the calcium phosphate method and $11.4 \%$ for the liposome method (lipofectamine, invitrogen). The electrospray method had a better efficiency (25-69\%) than that obtained using other gene introduction reagents under the same conditions. The high efficiency was not restricted to $\mathrm{CHO}$ cells, as Jurkat cells were also transfected at a relatively high efficiency (45\%) by electrospraying $5 \times \mathrm{PBS}$ at $-12 \mathrm{kV}$ (Figure 2). Jurkat cells normally grow in unattached culture medium; however, for this experiment, the cells were attached via polyethylenimine coating to the surface of the culture dishes. It was found that unattached and floating cells were not transfected by the electrospray method.

We were also able to demonstrate high efficiency transfection with protein. Approximately $50 \%$ of the cells preincubated with FITC-IgG antibody $(150 \mu \mathrm{g} / \mathrm{mL})$ and $93 \%$ preincubated with FITC-insulin $(2.5 \mathrm{mg} / \mathrm{mL})$ were detectable by fluorescence microscopy after electrospraying $3 \times$ PBS at $-12 \mathrm{kV}$ (Supplementary Figure S1). Apparently, proteins such as insulin $(6 \mathrm{kDa})$ and $\operatorname{IgG}(15 \mathrm{kDa})$, which are both around 2 orders of magnitude smaller than the test plasmid DNA (2.8 MDa), could also be transported relatively efficiently into cells by the electrospray method (Supplementary Figure S1).

We introduced a bacterial cell into a eukaryotic cell to demonstrate that transfection is possible even with a relatively very large particle. $\mathrm{CHO}$ cells preincubated with $\mathrm{E}$. coli that contained the plasmid pEGFP-N1 were electrosprayed at $-12 \mathrm{kV}$, and, although the efficiency of this transfection was very low $(0.003 \%)$, we did observe a GFP-positive $\mathrm{CHO}$ cell (Supplementary Figure S2). However, we conclude that introducing such large particles into cells is very difficult.

Other transfection methods. A fragrance atomizer and free-falling droplets can also induce transfection, and there is no charge on those droplets (Table 2). The method works using gas rather than liquid as the spray "medium". We tested air, carbon dioxide, and dimethylether with our device (Supplementary Figure S3). In these conditions, the gas velocity $(100-400 \mathrm{~m} / \mathrm{s})$ is higher than that of the droplets because gas has low density and a high compression rate.

\section{Discussion}

Apparently, ionic solutes in the electrospray medium favour higher transfection efficiency than nonionic ones. We therefore focused on conductivity as the primary electrophysical factor that is associated with ionic material. The relationship between electric conductivity and gene transfection efficiency is displayed graphically in Figure 2. The results showed that the water level was low $(0.8 \%)$. The transfection efficiency increased dramatically to higher than $60 \%$, with maximum efficiency obtained between $40-80 \mathrm{mS} / \mathrm{cm}$ conductivity. On the other hand, $10 \times$ PBS, which had the highest conductivity $(132 \mathrm{mS} / \mathrm{cm})$, caused an unstable spray by spark discharge. The unstable spray resulted in low transfection efficiency. In contrast to the sizable influence of electric conductivity on the success of transfection, we were able to identify factors that do not appreciably 
a

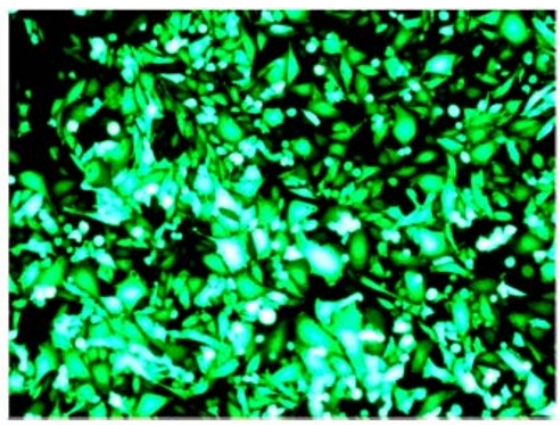

c

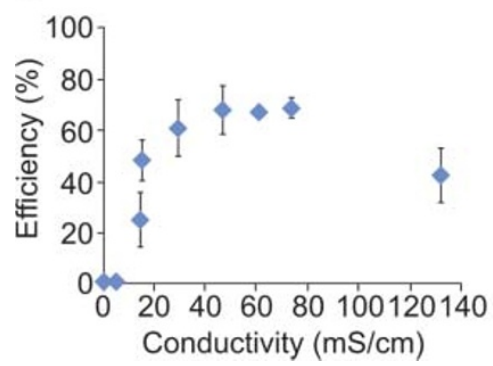

d

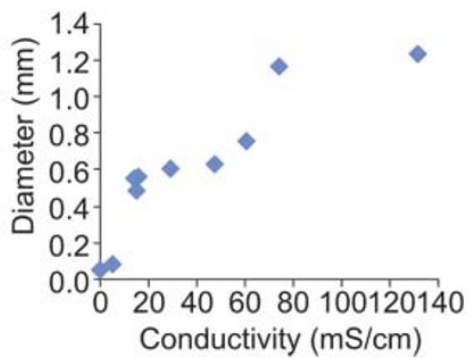

b

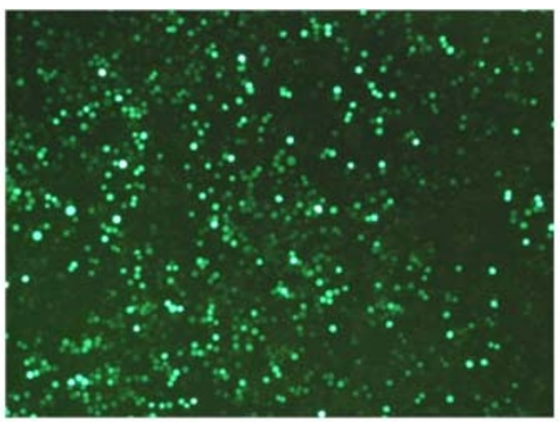

e

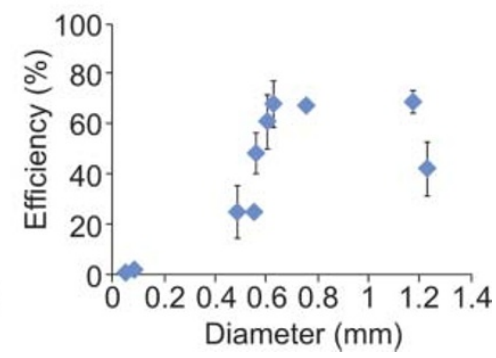

Figure 2 Electrospray transfection by conductive liquids. (a) Microphotograph of GFP expression in CHO cells induced by electrospraying ( $5 \times$ PBS, $-12 \mathrm{kV})$. (b) Microphotograph of GFP expression in Jurkat cells induced by electrospraying ( $5 \times$ PBS, $-12 \mathrm{kV})$. The cells were attached to the polyethyleneimine coating dish. (c) Transfection efficiency in CHO cells electrosprayed at $-12 \mathrm{kV}$ depends on conductivity. (d) Averaged diameter of droplets at $-12 \mathrm{kV}$ vs. conductivity of electrospray liquids. (e) Transfection efficiency vs. diameter of droplet.

influence transfection. Among these are molecular weight, type of cations and anions in the spray solution, and osmotic pressure.

Next, the diameter of the droplet was measured microscopically for study of the relationship between increasing conductivity and efficiency. The average diameter of droplets rapidly increases (more than $0.5 \mathrm{~mm}$ ) until a conductivity of $15 \mathrm{mS} / \mathrm{cm}$ is reached, after which it tends to reach plateau (Figure 2).

The diameter of all liquid droplets was $5 \mathrm{~mm}$ at $0 \mathrm{~V}$ (data not shown). Subsequently, the droplet charged by the application of high voltage was dispersed by surface electrostatic force, but the high conductivity liquid was difficult to charge and converted into large droplets. The graph pertaining to efficiency and diameter shows that gene introduction depended on the size of the droplet (Figure 2), and $70 \%$ of the cells were transfected when the droplet diameter was $0.5-$ $1.2 \mathrm{~mm}$. These results indicate that the actual diameter of the droplets was larger than that of the cells, and larger droplets were associated with relatively higher transfection efficiencies.

Furthermore, we performed a detailed analysis of applied voltage, droplet size, and transfection efficiency in varying ionic electrospray solutions. Water and solutions containing high concentrations of PBS (Hi-PBS) were compared. The transfection efficiency of most liquids depends on the applied voltage. The relationship between applied voltage and the droplet size was small between -8 and $-12 \mathrm{kV}$

Table 2 | Comparison of transfection performed using electrospray, atomizer, free-falling, and gas flow

\begin{tabular}{lllll} 
& Electrospray & Atomizer & Free-falling & Gas Flow \\
\hline Size $(\mathrm{mm})^{\mathrm{a}}$ & $0.1-1.2$ & 0.12 & 5.0 & - \\
Volume $^{\mathrm{b}}$ & $30 \mathrm{uL}$ & $50-60 \mathrm{uL}$ & $300 \mathrm{uL}$ & $0.4 \mathrm{~L}$ \\
Velocity $\left(\mathrm{ms}^{-1}\right)$ & $1.8-2.1$ & $5-8$ & $1.5 \mathrm{~m}$ height & $136-380$ \\
Efficiency $(\mathrm{CHO})$ & $40-80 \%$ & $1.80 \%$ & $0.30 \%$ & $8.1 \%$ \\
Charge & Yes & $\mathrm{No}$ & $\mathrm{No}$ & $\mathrm{No}$ \\
\hline $\begin{array}{l}\text { DDroplet diameter. } \\
\text { bTotal spray volume. }\end{array}$ & & & \\
cTransfection efficiency: GFP positive cells per total cells. & & \\
\hline
\end{tabular}

in Hi-PBS (data not shown). In solutions with high electric conductivity, such as $5 \times$ and $10 \times$ PBS, efficiency is higher at low voltage because the droplet sizes are larger (Figure 3 ).

We measured the average velocity of the electrosprayed droplets by high-speed photography. From those data, we calculate the mean to be approximately $2 \mathrm{~m} / \mathrm{s}$ lower than that that seen reported in DESI and ESI-MS $(0.1 \mathrm{~km} / \mathrm{s})^{13,14}$ (data not shown). Our methods cannot be used for measurements of the individual size and velocity of droplets. However, it is thought that the mean values reflect individual velocity and size because the typical size distribution curve of the electrosprayed droplets is very sharp.

In the distribution of droplet diameter at $-12 \mathrm{kV}$, the effective size is $0.1-1 \mathrm{~mm}$, and gene introduction is difficult with droplets smaller than this size (Figure 3). Before beginning the analysis of electrospraying transfection, we speculated that electrosprayed droplets would be very small compared with the size of a cell, and that the micro-droplets would perforate the cell membrane by causing mechanical damage. However, the actual diameter of the droplets is about $10^{2}$ times larger than that of the cells.

The finding that larger droplets result in higher transfection efficiency leads to the hypothesis that the most critical parameter for transfection is the impact energy generated by the collision of large droplets. Possibly related to this observation is the fact that a large projectile is effective at ionization in secondary ion mass spectrometry ${ }^{15,16}$. The total energy density associated with spraying cells is calculated from the spray volume and droplet velocity. Water and $10 \times$ PBS have the same energy density at $-12 \mathrm{kV}$ (Figure 3 ). However, it is not the resulting total energy that is important, but rather the energy of each droplet. We think that contact time, i.e. the time required for transfer of the collision energy, is an important factor for the simple mechanism of energy transfer. The contact time that delivers a good transfection rate is between $10^{-5}$ and $10^{-6} \mathrm{~s}$, depending on the diameter of the droplet. Our current interpretation would be that small droplets are not capable of delivering sufficient transfer energy for efficient transfection of DNA, but rather large droplets are effective conduits for energy transfer once they have contacted cells. 

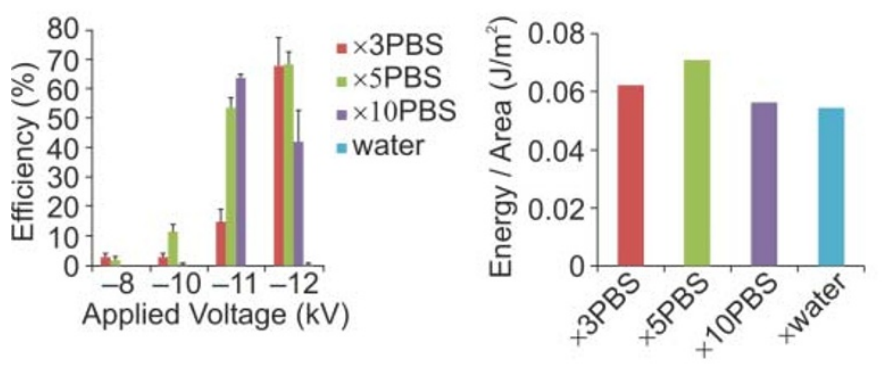

c

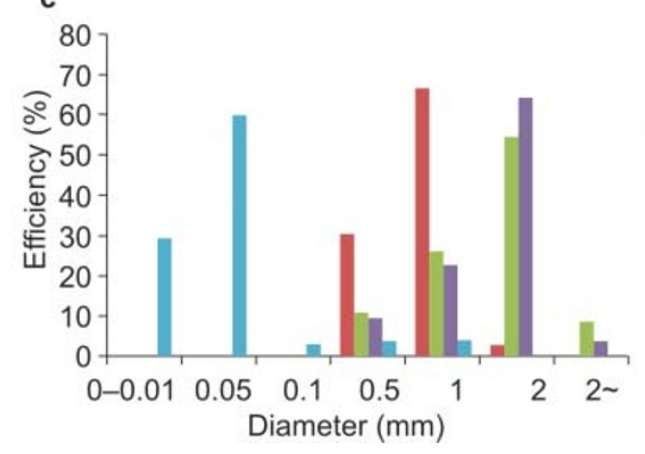

d

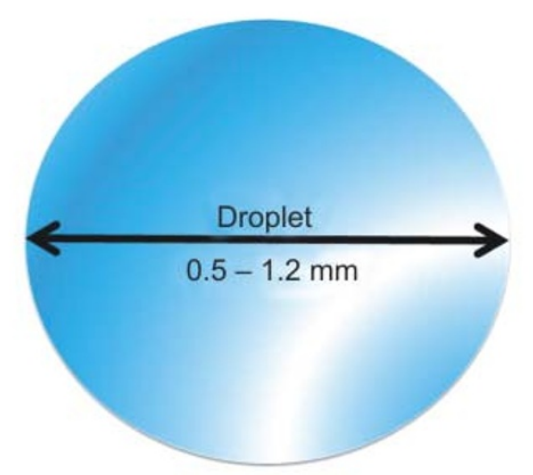

$=\times 3$ PBS

$=\times 5$ PBS

$=\times 10$ PBS

"water

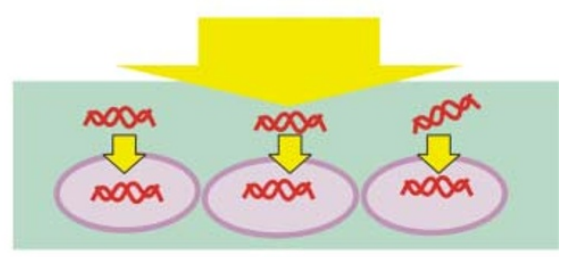

Figure 3 Droplet analysis and transfection mechanism. (a) Transfection efficiency in CHO cells depends on the average diameter of droplets at $-12 \mathrm{kV}$ and the concentration PBS (Hi-PBS) and water. Transfection efficiency is high at -11 and $-12 \mathrm{kV}$ in Hi-PBS, and a maximum efficiency of $0.8 \%$ is attained at $-12 \mathrm{kV}$ in water. (b) Calculated energy density of total electrospray at $-12 \mathrm{kV}$. Energy density of total spray to cells is calculated by the following equation: $\mathrm{E}=\left(1 / 2 * \mathrm{aLv}^{2}\right) / \mathrm{D}$, a: liquid gravity, L: spray volume, v: droplet velocity, D: dish area. (c) Number distribution of droplet diameter at $-12 \mathrm{kV}$, water is under $0.05 \mathrm{~mm}$ and $3 \mathrm{X}$ PBS is $0.1-1 \mathrm{~mm}$, and higher conductivity is shifted to a larger size. d) Scheme: Transfection mechanism of droplets strike.

Furthermore, the function of the droplets was examined with a fluorescent dye (FITC-glucosamine), which does not pass through a cell membrane. We compared electrospraying the dye vs. simply incubating cells in it, with $3 \times \mathrm{PBS}$ as solute. Although strong cellular fluorescence was seen with the electrosprayed dye, only slight fluorescence was seen with cells incubated in dye (Supplementary Figure S4). We conclude that the droplets generated by electrospray greatly enhanced the uptake of the dye.

The collision of a droplet with a cell indirectly makes the cell permeable; therefore, the droplet promotes cellular uptake of DNA. Electrospraying with a gene gun has been reported ${ }^{17}$, but this method has a different mechanism than described here. The pressure accompanying droplet impact is around $10^{3}-10^{4} \mathrm{~Pa}$; however, this is too low to induce gene transfection. We postulate that vertical collision induces a change of the cell's shape, and this somehow raises the permeability for gene transport. The electric charge per volume is small in large droplets. Similar characteristics can easily be produced by other spraying methods. Hence, we conclude that electrical charge on a droplet is not important for transfection by this method in mammalian cells.

As an interesting side observation, the velocity and diameter of the droplets are similar to those of rain droplets (terminal velocity of $0.7-$ $4 \mathrm{~m} / \mathrm{s}$; diameter from $0.2-1 \mathrm{~mm}^{14}$ ), and thunder clouds can impart an electrical charge to the rain droplets ${ }^{18}$. From the results of our electrospray experiments, one could even speculate that thundershowers may be involved in some way with horizontal gene transfer in nature ${ }^{19}$.

The electrospray method described here is very different from other techniques of gene delivery. It is very surprising that cellular DNA or protein uptake would be facilitated by a macroscale event, i.e. collision with a droplet much larger than the cell target. This macroscale method for transfection may offer a much more efficient, simpler, and more rapid technique for many types of cells.

In summary, we have achieved very high transfection efficiencies for genes and proteins by an electrospray method. Both a normal liquid spray and gas flow successfully induced transfection of cells. We obtained surprising results showing that oversized droplets, around 100-times larger than cells, gave the highest transfection activity. This method is enhanced by increasing the size of droplets and raising the applied voltage, and it does not require any special reagents. In addition, the underlying mechanisms may have some relevance for horizontal gene transfer during evolution.

\section{Methods}

Cells and culture conditions. Cell lines were maintained in culture medium supplemented with $10 \%$ foetal bovine serum (FBS) and antibiotics in a $5 \% \mathrm{CO} 2$ atmosphere at $37^{\circ} \mathrm{C}$. Minimum essential medium (alpha-MEM) was used for Chinese hamster ovary (CHO) cells, and RPMI1640 medium was used for Jurkat cells. For transfection experiments, cells were plated in poly-L-lysine-coated 35-mm culture dishes at a density of 10,000 cells/dish. GFP cellular fluorescence was visualized by fluorescence microscopy, and transfection efficiency is expressed as the proportion of GFP-positive cells per total cells in the confluent monolayer.

Insulin- and IgG-FITC conjugation. Fifty $\mathrm{mg}$ of bovine insulin was diluted with $0.5 \mathrm{~mL}$ of a buffered solution containing $2.8 \% \mathrm{NaHCO}_{3}$ and $1.7 \% \mathrm{Na}_{2} \mathrm{CO}_{3}(\mathrm{w} / \mathrm{v})$. Then FITC $(11 \mathrm{mg})$ was added to the insulin solution and incubated at room temperature for $1 \mathrm{~d}$. The mixed insulin FITC solution was dialyzed for 1 wk with a thermo slide lyzer Mz3000 and then lyophilized. The dried insulin-FITC conjugated proteins were redissolved in water at a concentration of $2.5 \mathrm{mg} / \mathrm{mL}$. Similarly, IgG $(\mathrm{H}+\mathrm{L})$ VEC b1-1488 was conjugated with FITC and redissolved at a concentration of $150 \mu \mathrm{g} / \mathrm{mL}$.

Electrospray transfection. The insulator (PEEK) nozzle $(0.25-\mathrm{mm}$ calibre and length of $20 \mathrm{~mm}$ ) was connected to a metal tube, to which high voltage was applied. The cells and GFP plasmid ( $10 \mu \mathrm{g}$ in $100 \mu \mathrm{L}$ of water) in a poly-L-lysin coating $35-\mathrm{mm}$ polystyrene dish were connected to a ground potential plate by a metal ribbon. After $5 \mathrm{~min}$, the whole area of the dish was sprayed by the moving nozzle (moving speed of $5 \mathrm{~mm} / \mathrm{s}$ ). Scanning conditions included a $40-\mathrm{mm}$ line with $6-\mathrm{mm}$ intervals at a liquid flow rate of $6 \mathrm{~mL} / \mathrm{h}$. Fresh culture medium was added immediately after electrospraying, and the cultures were examined by fluorescence microscopy after 1 day of incubation following transfection.

Atomizer and free-falling transfection. An everyday household atomizer $(3 \mathrm{~mL}$ in volume) was purchased and was determined to release a volume of $50-60 \mu \mathrm{L}$ with each spray. After removing culture medium from a $35-\mathrm{mm}$ dish containing $\mathrm{CHO}$ cells, the cells and GFP plasmid (10 $\mu \mathrm{g}$ in $100 \mu \mathrm{L}$ of water) were preincubated for 
$5 \mathrm{~min}$. A solution of $1 \times$ PBS was then sprayed from the atomizer from a height of $5 \mathrm{~cm}$ above the cell monolayer, after which fresh culture medium was added. For the free-falling transfection method, the PEEK nozzle was used. After removal of the culture medium, CHO cells and GFP plasmid were preincubated as just described, after which droplets of $1 \times$ PBS were dropped from the tip of the nozzle at a height of 1.5 or $0.75 \mathrm{~m}$ using a pump. After a sufficient number of droplets to cover the whole area of the dish had fallen onto the monolayer, fresh medium was added.

Gas flow transfection. The electrospray device was modified by replacement of the liquid line with a gas line and was used to direct a stream of air and carbon dioxide $\left(\mathrm{CO}_{2}\right)$ onto cell monolayers. The gas flowed over a monolayer of $\mathrm{CHO}$ cells and DNA (as described for the other methods above), directed from a height of $1 \mathrm{~cm}$ by the $0.25-\mathrm{mm}$ calibre nozzle moving at $5 \mathrm{~mm} / \mathrm{s}$. Scanning conditions included a 40-mm line with 3-mm intervals at each gas flow speed that was tested. To test dimethylether (9:1 mix with freon) as the gas sprayed over the monolayers, an air duster can was used.

Measurement of the velocity and size of droplets. The velocity of the droplets was measured visually using a high-speed camera (Casio FH-20). The droplets were electrosprayed on an indium tin oxide/polyethylene terephthalate film. Immediately after spray, droplets were mixed with silicone oil and observed with a microscope.

1. Boussif, O. et al. A versatile vector for gene and oligonucleotide transfer into cells in culture and in vivo: polyethyleneimine. Proc. Natl. Acad. Sci. U.S.A. 92, 72977301 (1995).

2. Nyunt, M. T. et al. Physico-chemical characterization of polylipid nanoparticles for gene delivery to the liver. Bioconjug. Chem. 20, 2047-54 (2009).

3. Klein, T. M., Wolf, E. D., Wu, R. \& Sanford, J. C. High-velocity microprojectiles for delivering nucleic acids into living cells. Nature 327, 70-73 (1987).

4. Stevenson, D. J., Gunn-Moore, F. J., Campbell, P. \& Dholakia, K. Single cell optical transfection. J. R. Soc. Interface. 7, 863-71 (2010).

5. Fenn, J. B., Mann, M., Meng, C. K., Wong, S. F. \& Whitehouse, C. M. Electrospray ionization for mass spectrometry of large biomolecule. Science 246, 64-71 (1989).

6. Cooks, R. G., Ouyang, Z., Takats, Z. \& Wiseman, J. M. Ambient mass spectrometry. Science 311, 1566-1570 (2006)

7. Chen, H., Zhao, Y., Song, Y. \& Jiang, L. One-Step Multicomponent Encapsulation by Compound-Fluidic Electrospray. J. Am. Chem. Soc. 130, 7800-7801 (2008).

8. Loscertales, I. G., Barrero, A., Márquez, M., Spretz, R., Velarde-Ortiz, R. \& Larsen, G. Electrically Forced Coaxial Nanojets for One-Step Hollow Nanofiber Design. J. Am. Chem. Soc. 126, 5376-5377 (2004).

9. Okubo, Y., et al. DNA introduction into living cells by water droplet impact with electrospray process. Angew. Chem. Int. Ed. 47, 1429-1431 (2008).
10. Kebarle, P. \& Tang, L. From ions in solution to ions in the gas phase-the mechanism of electrospray mass spectrometry. Anal. Chem. 65, 972-986 (1993).

11. Drozin, V. G. The electrical dispersion of liquids as aerosols. J. Colloid. Sci. 10 158-164 (1955)

12. Cheng, X. et al. Molecular Weight Determination of Plasmid DNA Using Electrospray Ionization Mass Spectrometry. Nucl. Acids Res. 24, 2183-2189 (1996).

13. Nemes, P., Marginean, I. \& Vertes, A. Spraying mode effect on droplet formation and ion chemistry in electrospray. Anal. Chem. 79, 3105-3116 (2007).

14. Venter, A., Sojka, P. E. \& Cooks, R. G. Droplet dynamics and ionization mechanisms in desorption electrospray ionization mass spectrometry. Anal. Chem. 78, 8549-8555 (2006).

15. Hiraoka, K., Asakawa, D., Fujimaki, S., Takamizawa, A. \& Mori, K. Electrosprayed droplet impact/secondary ion mass spectrometry. Eur. Phys. J. D 38, 255-229 (2006).

16. Cornett, D. S., Lee, T. D. \& Mahoney, J. F. Matrix-free desorption of biomolecules using massive cluster impact. Rapid Commun. Mass Spectrom. 8, 996-1000 (1994).

17. Chen, D., Wendt, C. H. \& Pui, D. Y. H. A novel approach for introducing biomaterials into cells. J. Nanoparticle Res. 2, 133-139 (2000).

18. Ahrens, C. D. (2007). Meteorology today. 8th edition, Japanese version. Tokyo: Maruzen Co., Ltd.

19. Ceremonie, H., Buret, F., Simonet, P. \& Vogel, T. M. Isolation of lightningcompetent soil bacteria. Appl. Environ. Microbiol. 70, 6342-6346 (2004).

\section{Author contributions}

K.I. conceived and designed this study and performed experiments. K.I., I, S. and T.S. discussed and analysed the results and shared the writing of the paper.

\section{Additional information}

Supplementary information accompanies this paper at http://www.nature.com/ scientificreports

Competing financial interests: The authors declare no competing financial interests.

License: This work is licensed under a Creative Commons

Attribution-NonCommercial-ShareAlike 3.0 Unported License. To view a copy of this license, visit http://creativecommons.org/licenses/by-nc-sa/3.0/

How to cite this article: Ikemoto, K., Sakata, I. \& Sakai, T. Collision of millimetre droplets induces DNA and protein transfection into cells. Sci. Rep. 2, 289; DOI:10.1038/srep00289 (2012). 